\title{
Embracing ambiguity in the design of non-stigmatizing digital technology for social interaction among senior citizens
}

\author{
T. SOKOLER* and M. S. SVENSSON* \\ Blekinge Institute of Technology, School of Engineering and School of Health Science, \\ Box 520, SE-37225 Ronneby, Sweden
}

In this paper we report our early experience with the design of technology for senior citizens. We take as our point of departure a pre-study of the ways in which older adult living occurs at three different senior housing facilities in southern Sweden. We contribute to the current debate concerning the ways in which digital technology can be designed to enable new types of living arrangements for the ever growing population of older people. We focus on technology designed to support the social rather than physical challenges of growing older. In particular we discuss how designing for social interaction can circumvent the stigma associated with being lonely in light of diminishing social networks, changed patterns of interactions with family, moving to a new neighbourhood, and the loss of a spouse. We will suggest that designers, in the design of digital technology for social interaction, deliberately leave room for ambiguity to make it possible for people to leave their intentions of use unarticulated. Furthermore, recognizing that many everyday activities already act as enablers for social interaction, we suggest utilizing such activities as an approach for design. We will support our suggestions by introducing three perspectives: a perspective emphasizing that the population of older adults is one of resourceful individuals; a perspective on social interaction emphasizing its circumstantial nature as an inherent part of everyday activities; and a perspective on the role of digital technology emphasizing its role as merely one of many resources present for human action. Finally, we will present an example concept showing how an enhanced TV remote control may be designed to enable social interactions without inflicting too much on the original experience of watching TV and most importantly, without stigmatizing the people using the remote control as lonely individuals craving the company of others.

Keywords: Senior citizens; Social interaction; Ambiguity; Stigmatization; Interaction design

\section{Introduction}

Most western world societies recognize that they will eventually face an imbalance between a diminishing group of active people generating revenues and an ever-growing group of retired people needing support (Thorslund and Parker 1995). Political decision and the general economical development will obviously be the most important forces when meeting this so-called 'demographic challenge'. There is, however, an ever-growing belief that technology and in particular digital technology may help us meet this challenge.

Consequently, major tech industry players and academia have formed alliances with groups representing the interests of senior citizens in order to explore how digital technology can act as an enabler in the shaping of new types of lives and living arrangements for the population for older adults (Dalrymple 2005, Rantz et al. 2005). Aging-in-place is the overarching figure of thought brought forward and explored through these alliances. The core idea being that

*Corresponding author. Email: Tomas.sokoler@k3.mah.se; marcus.sanchezsvensson@bth.se

Behaviour \& Information Technology

ISSN 0144-929X print/ISSN 1362-3001 online @ 2007 Taylor \& Francis

http://www.tandf.co.uk/journals

DOI: $10.1080 / 01449290601173549$ 
digital technology should be designed to help senior citizens stay in their own homes as long as possible and live independent lives to the fullest extent possible by the means of various kinds of assistive technologies. Hence, it is implied that they will stay in their original home and furnish the living space with the assistive digital technology needed to accommodate their individual process of growing older. This of course would not only serve a desire to stay in their own homes as expressed by a majority of senior citizens but would even, it is argued, at the same time, help society meet the demographic challenge by lowering the cost of care per senior citizen. The range of assistive technologies brought forward is wide and includes health and accident monitoring systems, home automation technologies, and different forms of robotic assistance (Chan et al. 2002, Cole and Tran 2002, Das and Cook 2004, McFadden and Indulska 2004, Perry et al. 2004, Sixsmith and Johnson 2004).

While most of the assistive technologies brought forward so far have been aimed at overcoming functional disabilities it is increasingly recognized that more attention needs to be directed towards technology designed to support the social and emotional aspects of growing older. Based on a study of the needs of older people in a senior community, Hirsch et al. (2000) argues that we need to consider not only independence but also engagement as a crucial factor affecting the quality of life. In brief, engagement concerns the relationship and connectedness of older people to other people in a community. Concerns with the dimension of social engagement have encouraged researchers to develop technology to foster companionship and support community network (Consolvo et al. 2004, Brunette et al. 2005). This implies a shift in focus from the more tangible aspects of growing older such as reduced mobility and loss of senses, for example, to the social aspects of growing older such as diminishing social networks, changed patterns of interactions with family, moving to a new place with new neighbours, and the loss of a spouse. Our work presented in the present paper follows this shift of focus and explores the design of digital technology that aims to support social interaction amongst a group of senior citizens.

In general, as we start exploring the use of assistive technologies in the context of older people's everyday lives it becomes evident that the success and acceptance of these technologies not only depends on the functionality offered but also depends on how the person using the technologies feels and experiences how she/he is being perceived and treated by others. In other words, assistive technology that makes people feel embarrassed and ashamed of using it is destined to fail. As pointed out by Hirsch, the difference between 'can' be used and 'will' be used is directly linked to the notion of non-stigmatizing versus stigmatizing technology - non-stigmatizing digital technology meaning technology that can be used without putting the older people on display as disabled, needy, weak or in any other way as pathetic individuals. Thus, in the design of assistive technologies for independent living such as wheelchairs, alarm devices, and health monitoring systems decisions on form, colour and physical expressions are crucial for the success of these technologies. As we turn to the design for engagement and social interaction we will argue that less tangible, however just as important, factors need to be considered as part of the design in order to succeed. In particular, we will discuss how a design for electronically mediated social interaction needs to somehow circumvent the taboo of loneliness and hence the stigma associated with being lonely. Despite the fact that the majority of the people in the communities we studied live alone - and that loneliness clearly is a theme of great relevance - we find that loneliness is tabooed and something people are very reluctant to talk about or in any way expose. Hence, people will not appreciate and consequently not make use of a technology for social interaction if the use of this technology singles out them as lonely individuals in need of company. Hence, we are faced with a rather eccentric challenge of designing technology that, even though it is designed to bring people together and address the problem of loneliness through mediated social interaction, cannot in anyway reveal that this is why people use the technology in question. In this paper we will reflect upon this challenge and, in more general terms, the difficulties faced in the design of nonstigmatizing digital technology for social interaction.

We will argue that the designed technology needs to allow for some level of uncertainty, leaving room for multiple interpretations of the underlying intentions of use. Following the line of thinking presented by, amongst others, Aoki and Woodruff (2005) and Gaver et al. (2003) we will talk about this as a strategy that exploits ambiguity as a resource in the design for social interaction - that we, in the design of technology should embrace the kind of ambiguity that people already experience and take advantage of in face to face social interactions throughout everyday activities. We will suggest that we seek a particular symbiotic relationship between mediated social interaction, ambiguity and everyday activities. That is, we will suggest that the overall strategy of 'embracing ambiguity' can be advanced by utilizing existing everyday activities. The rationale being that, everyday activities in general can be seen, and already work as, providers of openings for social interaction. In terms of design this implies, as we will discuss, that we may turn away from the design of generalpurpose monolithic systems towards smaller highly dedicated designs that aim to be fully integrated with an already occurring, and in its own right, purposeful activity.

The current paper will present ideas and reflections on the design for older people rather than results of concrete experiments and evaluations. We will discuss the above suggestions and relate them to a) a field study conducted at 
three different senior housing facilities, b) our prior experience in the field of interaction design for ubiquitous computing, and c) existing sociological literature on everyday social interaction. Our discussion will be supported by three particular developed perspectives: First, a perspective on the population of older adults emphasizing that it is a population of resourceful individuals; second, a perspective on social interaction emphasizing its circumstantial nature as an inherent part of everyday human activities; and third, a perspective on the role of digital technology emphasizing its role as merely one of many resources present for human action in the world. Finally, we present an example concept that illustrates the kind of digital technology that may follow from the overall thinking and suggestions presented.

\section{Design perspective and analytical orientation}

This paper reports on our early experience with the design of technology for senior citizens and takes as its starting point a relatively short pre-study of the ways in which living plays out at three different senior housing facilities in southern Sweden. The three facilities differed in number of people and houses/apartments, age distribution, organisation and community policy. We set out to better understand everyday life and social interaction in these senior housing facilities and to reflect upon the challenge of designing technology that can improve quality of life.

Our study was driven by a series of visits. During these visits we had the opportunity to conduct interviews with people in their own homes while being guided through the facility. We interviewed three people on an organizational level and ten older adults living in the facilities we visited. For the people living at the three facilities growing older has involved leaving their home and moving into a new living arrangement and different community. However, in these housing facilities the older people still live in their private self-contained apartments/houses. The type of senior housing facilities in question are by no means as care intensive as nursing homes but still require more resources (cantina, reception, administration) than ordinary homes. In order to obtain broader views we also arranged discussions and interviews with other senior interest groups not living in senior housing communities.

In general, our way of understanding and making social inquiries into the world of older adults and people living in communities of older people has been informed by a particular analytical orientation to social interaction in everyday life; an analytical orientation that is influenced by ideas and ways of thinking about the individual in the social world introduced and discussed in the writings of influential social thinkers (Garfinkel 1967, Goffman 1959, Sacks 1992).

\subsection{Older people and the stigma of loneliness}

In our studies we have encountered and made some observations of the everyday lives of a large group of older people in the age of 55 and above. It is a diverse group of people that has moved into new living facilities who may be still working, some getting ready to retire and some already retired, some living alone and some living with a partner. However, these people are still relatively healthy, active and resourceful people - they are not patients or people in need of home assistance. It is a group of people with different backgrounds and interests who are in a stage of life that in no way can be defined in terms of age or as a well-defined final state. Rather, ageing is a continually ongoing process with many faces. We have learned that many older adults in this group of people do not want to be seen and treated as patients. Even though they realize that medical care is an inevitable part of life they do not want to be constantly and openly associated with that aspect of growing older - here we have people who still have time, money and energy to live independent and active lives. As noted by one of the inhabitants in a senior-living community area:

'It was delightful to retire. I found my freedom. Finally, I have the time to do whatever I want to while still full of life and healthy'.

Despite the fact that these people are resourceful and capable individuals we have recognized that they sometimes face a pressing problem in their everyday lives, namely the problem of loneliness (figure 1). Many of the people we have encountered are today living alone in these senior housing communities. It is clear that the stage of life when deciding to retire and perhaps move to a new place involves issues of loneliness. People who have lost their partner may also have lost contact with family members and old friends. However, the issue seems not only to be that people are living alone and are feeling lonely, but that loneliness is something people do not explicitly talk about and something they do not want to be associated with. We have come to understand that loneliness can become a type of stigma - a particular social identity or individual character/attribute that singles him/her out as negatively different in relation to others in the community (Goffman 1963, 1967). Many people in situations of loneliness seem to make a distinction between being alone and being lonely. People are often perfectly fine being alone and living on their own, but they appear to be more concerned with the social image of them as being sad and lonely - an image that people do not want to participate in conveying and that sometimes leads to people hiding and disengaging from social relations.

Even though people living alone may have accepted for themselves that they are as normal as everyone else, they 


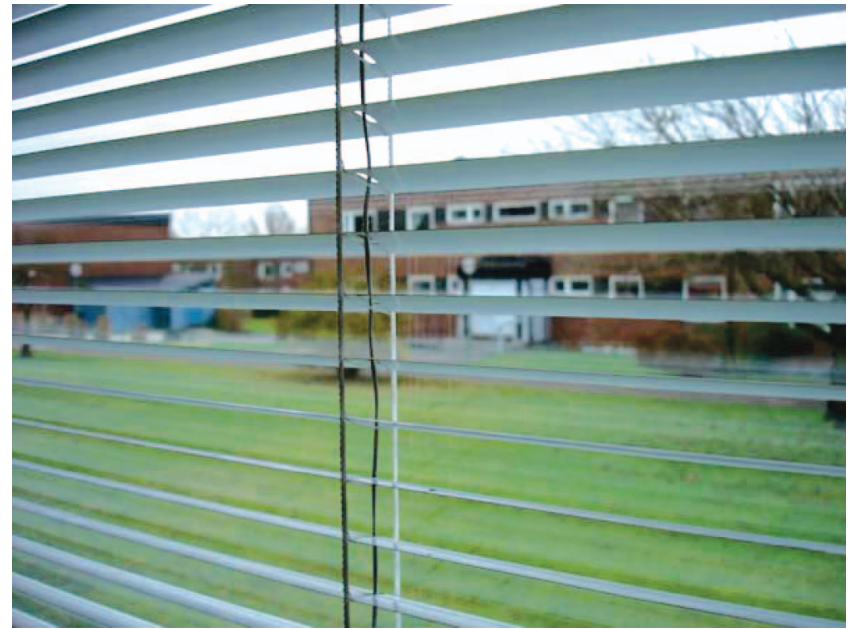

Figure 1. Loneliness and social isolation is an issue for many older people.

seem to believe that their deviant social situation will not be accepted by other 'normals' on equal grounds. That is, individuals may believe that they are putting themselves and others in a situation where other people would have to behave and design their appearances and impressions in certain ways in order to avoid potential embarrassments when explicitly exposed and talked about. One of the ways in which we have encountered this phenomenon is how the older adults talk and reason about how they are different, misplaced, and put in difficult situations because of their loneliness. For example, one of the situations often talked about occurs when being invited to a dinner. As one of the ladies told us:

'It is not easy being on your own and getting to know new people. One of the reasons is that around here only couples meet couples. Couples never appear very often at the social gatherings. It would be awkward being invited to such an event as an individual without a partner.'

Evidently, a single female invited to a dinner of couplesonly may withdraw from this event because the risk of being seen as miserable lonely and for the reason of saving others from giving lip service, which in the end is what makes the shamed person ashamed. Many people hide and avoid social contact because of the difficulties for themselves, and most importantly for others, to manage a stigma and the potential associated embarrassments.

One of the ways in which we have seen how community areas are trying to deal with problems of loneliness and disengaged social relations is to create and sustain an active social environment involving community dinners and interest groups.

'I often see who is newly moved in and I often ask if he or she wants to have dinner. I usually do this as a way of introducing new people. Once a month we arrange a social gathering dinner because so many people are lonely. Everyone gets a name tag to wear.'

However, we believe that the solution to the problem is more complex and subtle than that. We have learned that formally arranged community dinners for singles and people living alone are not always as appreciated or desired for obvious reasons - people simply do not want to tell or make explicit to others that they are lonely because it is embarrassing when becoming the topic of discussion. The issue here, which we will discuss in more detail, is that explicitness sometimes hinders social interaction. We believe that there are other ways people find as openings to social interaction that are less revealing and that do not increase the risk of people loosing face or being singled out because of their identity or particular social situation.

\subsection{Everyday activities as openings for social interaction}

We have begun to consider issues related to the problem of increasing social engagement and making contact with new people by viewing everyday activities as openings for social interaction. Everyday activities such as going on walks and doing the gardening provide a 'ticket to talk' (Sacks 1992) with unacquainted older people. People in these community areas do not always start to talk to people they are unacquainted with unless there are legitimate circumstances which provide an excuse or a basis for opening a conversation. Harvey Sacks (1992) writes about the ways in which the $\operatorname{dog}$ - when walking the dog in the park - is a 'ticket' to start having a conversation with people who they are previously unacquainted without it being treated as an unwelcome advance. We believe that the ways in which people present themselves and interact with others in everyday life builds on an inherent ambiguity of intentions and purposeful actions. People tend to say and do things less explicitly in order to save themselves from embarrassments and give room for impression management (Goffman 1959, 1967). We are arguing that many everyday activities in public or semi-public places open opportunities for social interaction because ambiguities and unspoken non-explicit intentions are inherent to those activities.

Our initial inquires into the everyday lives of people in senior housing communities revealed the importance of everyday activities as openings for social interaction. One of the social events that many people talk about with 
great joy is gardening in the spring and summer. As one enthusiastic female gardener told us:

'We sometimes encounter other people at the garden lots. We exchange plants, borrow equipment, and people stop by asking 'what kind of flower is that'? The garden lots are very social. There is a bench near the lots where people sit, watch and talk.'

For this lady, gardening is apparently not only something she likes to do because she enjoys growing flowers and plants. Rather, she and others appreciate it because garden lots are social. Gardening creates opportunities to meet new people by exchanging plants and equipment with other gardeners. It is a place where other people pass by on their daily walk which and where they can rest and perhaps engage in brief conversations with the gardeners or other passers-by (figure 2). This was particularly evident to us in the way in which this lady talked about the marvellous flower she grows every summer. She told us 'I have learned to grow a Hibiscus - a very difficult flower - and everyone wants to come and have a look'. For her, and in particular for others, growing the marvellous Hibiscus becomes a 'ticket' to talk with others.

The way in which gardening and other everyday activities are used as a vehicle for social encounters seems to relate to a delicate process of resolving the ambiguities of negotiating the balance between visibility (being noticed) and availability (open for social interaction). Doing the gardening, passing by or sitting down on the park bench next to the garden lots [allotments] is something people seem to do as part of an ongoing balance between 'making oneself noticed' and 'being open for opportunities' and being in control of the extent to which they are willing to move from the 'accidental' encounter to an actual interaction with other(s) present. People exploit the ambiguous circumstances of a particular encounter embedded in a particular familiar everyday activity as an excuse or a basis for a conversation. People make themselves noticed and discover opportunities for social interaction without signalling a craving for company in the way the encounter takes place as part of another familiar activity. Everyday activities and their social and physical circumstances - such as the dog and the marvellous flower - provide a common resource for human action.

This way of understanding social interaction has influenced the ways in which we want to place technology as a resource for increasing social engagement. We believe that opportunities for social engagement and feeling safe by being noticed is not only about chat-lines and panic buttons. We argue that it is important to embrace the ambiguities of everyday activities as a vehicle for people feeling noticed, being present in a network of caring peers and being open for social interaction.

\subsection{Digital technology as one of many resources for human action}

Our thinking about the design of non-stigmatizing digital technology for social interaction is guided by a perspective on the role of digital technology in general. This perspective is adopted from our prior work on how to meet the challenges we face when designing digital technology for domains of everyday life and hence, for situations of use that go beyond the office-world and the use of desktop computers (Sokoler 2004). The perspective presented stems from a general exploration of human-computer interaction design for ubiquitous computing and therefore relates to a large body of work within this field of research (e.g. Dourish 2001). In general, the perspective encourages us to
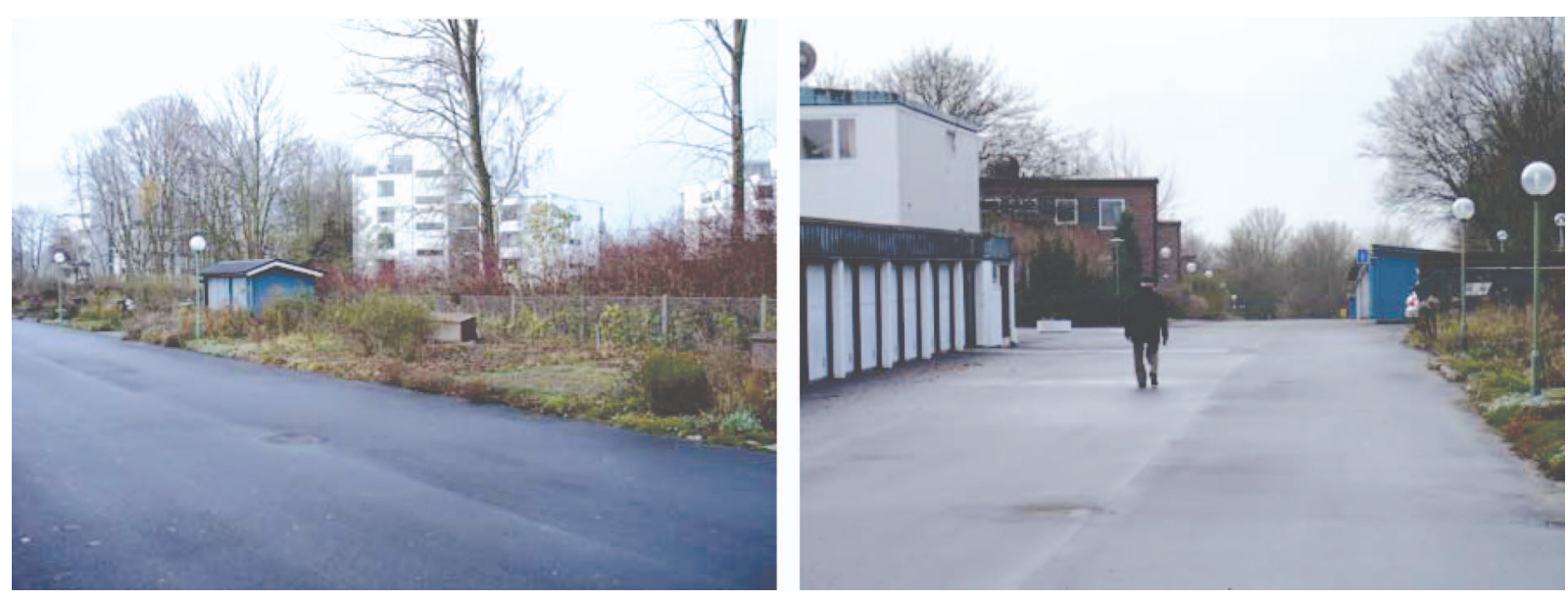

Figure 2. Gardening activities in the summer encourages chance encounters and conversations between passers-by and gardeners. 
leave an exclusive techno-centric model of use behind and look for more inclusive models that better align the technology we design with the many other resources for human action also present in the everyday world of human activities.

The perspective suggests two 'moves' to help us better accommodate, and in fact bring leverage to, the situated nature of interaction between humans and the technology we bring forward:

A move away from the design of monolithic all encompassing systems towards the design of a more 'humble' type of digital technology explicitly designed to become part of a larger patchwork of resources. Hence, we seek to make possible a constructive relationship between the digital technology we design, human skills, and the many other resources present in the setting of use. And, importantly, we look upon these skills and the other resources present as opportunities we can take advantage of rather than resources that we need to replace or obstacles we need to somehow overcome.

A move away from the design of 'thinking machines' towards the design of digital technology that brings advantage to, and reliance on, (rather than attempts to take over), the human ability to make decisions and take appropriate action when in complex physical and social settings. Hence, a move towards the design of suggestive and informing technology that leaves the human in control and, in fact, aims to take advantage of, not 'computerize', the tacit human ability to establish coherence between activities, technology, and setting of use.

In brief, the perspective is meant to help us recognize, embrace and take advantage of the fact that human interaction with the technology we design will take place, in a rich social and physical setting full of a wide range of resources for human action and not a vacuum.

As we will demonstrate in the following sections, this perspective on the role of digital technology immediately resonates with our thinking about the circumstantial and situated nature of social interaction, our thinking of older adults as resourceful individuals and our thinking on how to avoid stigmatization in the use of digital technology.

\section{Moving towards design}

In this section we will discuss the kind of design that may follow on from the general discussion and perspectives presented in this paper. As we move towards design we identify three themes originating from the perspectives presented above.

1. 'Allowing room for ambiguity by leaving things unsaid'.

2. 'Utilizing existing everyday activities when looking for enablers of social interaction'.
3. 'The integration of digital technology with other resources for human action'.

These three themes are interwoven and will be present as a conceptual canvas throughout the following discussion of a concrete example concept.

The example concept will illustrate how the idea of utilizing an existing everyday activity may lead to the design of digital technology that can bring forward openings for social interactions while preserving the ambiguity needed to avoid stigmatization. More specifically the concept will show how an enhanced TV remote control may be designed to enable social interactions and a sense of community belonging without inflicting too much on the original experience of watching TV and important, without stigmatizing the people engaging in the social interactions as needy individuals craving the company of others.

\subsection{Introducing a target domain for our design: $T V$ watching as an enabling everyday activity}

It should be of no surprise that TV watching is a very popular activity among the older people that we visited during our field studies. It is an everyday activity enjoyed at length by all the people we visited and interviewed. Also unsurprizingly, watching TV was predominantly an activity taking place at night and for all the older people living alone enjoyed in solitude. Watching TV on your own was not described as a problem in itself. As a matter of fact, a number of the interviewees were very explicit in expressing a desire to be in control of what they wanted to watch and talked about the advantage of not having to fight over the remote - something many of our interviewees had experienced when they were still living with their spouses. In general the interviewees talked about the hours of TV watching in positive terms as a time of relaxation 'curling up on the couch' with TV as company. With these observations in mind we started to look into a design that would build upon the original TV watching experience and enable openings for social interaction without redefining the original experience of watching $\mathrm{TV}-\mathrm{a}$ design that would allow the senior citizens in question to do what they already do but at the same time give them a chance to notice and be noticed within their community of peers.

In pursuit of this idea we noticed that there are TV technologies on the rise that aim to change the experience of watching TV, making it into a more community oriented and interactive experience. The so-called triple-play platform for the combined delivery of data, voice, and video over broadband networks and IPTV (internet protocol television) points towards a general shift in the role of TV viewers. This shift from broadcast TV to video-on-demand and from TV viewers taking the role of a passive audience 
to TV viewers becoming much more active participants in a network of peers with the ultimate goal of allowing all TV viewers to become providers of content to this network. In order to demonstrate the more engaging TV experience that a triple-play platform may provide Alcatel have suggested 'Amigo TV' (Vanparijs et al. 2004, Coppens et al. 2005, Bouwen et al. 2005). In brief Amigo TV turns TV watching into a shared interactive group experience taking place despite geographical distance between the individual group members. 'Amigo TV Application enables you to watch TV with your remote friends and family as if you were in the same room.' (Coppens et al. 2005).

In the discussion of our example concept we choose to contrast our design with AmigoTV as a way for us to better illustrate how our design goals differ from the predominant goal of turning the watching of TV into a more interactive experience. Amigo TV focusses on enabling synchronous communication amongst group members watching the same TV channel and revolves around the notion of remote presence and a highly dynamic game-like interaction between group members as they exchange comments on the TV content they are currently watching. By and logging on to Amigo you clearly signal that you are ready and expect to be part of a shared interactive experience. Logging on signals an explicit intention of wanting to hook up with your friends and share their company while you watch TV 'together'. In this way, AmigoTV dramatically changes the way we watch TV today and aims to be something quite different from our interviewees' idea of TV watching as a serene activity that allows you to get cosy on your couch. Our design goal is very different from that of AmigoTV. While Amigo aims to use new digital technology to change the activity of TV watching, our aim is to use digital technology to add a dimension of social interaction while keeping the original TV watching activity as intact as possible. We want to retain the quality of serenity that our interviewees have expressed as important to their TV watching, not turn the experience of watching TV into something that resembles an action-filled gameplaying experience. In other words, in accordance with our approach to the design for social interaction we are not looking to redesign the experience of watching TV but rather looking at ways to utilize TV watching as an existing everyday activity that can be used to make ways for openings to engage in social interactions.

Following a brief presentation of the functionality envisioned in our concept for an enhanced TV remote we will discuss the design rationale and how the concept reflects the overall thinking presented in this paper.

\subsection{Example concept: The PresenceRemote}

The 'PresenceRemote' (PR) is an enhanced TV remote control making it possible for you to notice others and be noticed within your community as you watch TV. In this context we will use community to mean people living within a geographically limited living facility for older people similar to the kind of facilities that we have visited. This implies that we are designing for an environment with ample opportunities for various kinds of social interaction, not least of course, face-to-face joint activities and chance encounters. Hence, in line with our thinking about the role of the digital technology the design we come up with should be regarded as a supplement to, rather than an all encompassing system that aims to replace, the already existing ways for the older people within the community to interact.

As shown in figure 3 the PR is basically a TV remote control with the addition of a colour display and three extra buttons. Below follows a brief description of its functionality:

1. When the PR is OFF it works as your ordinary TV remote control with no extra functionality and no information about TV activities, yours or others,

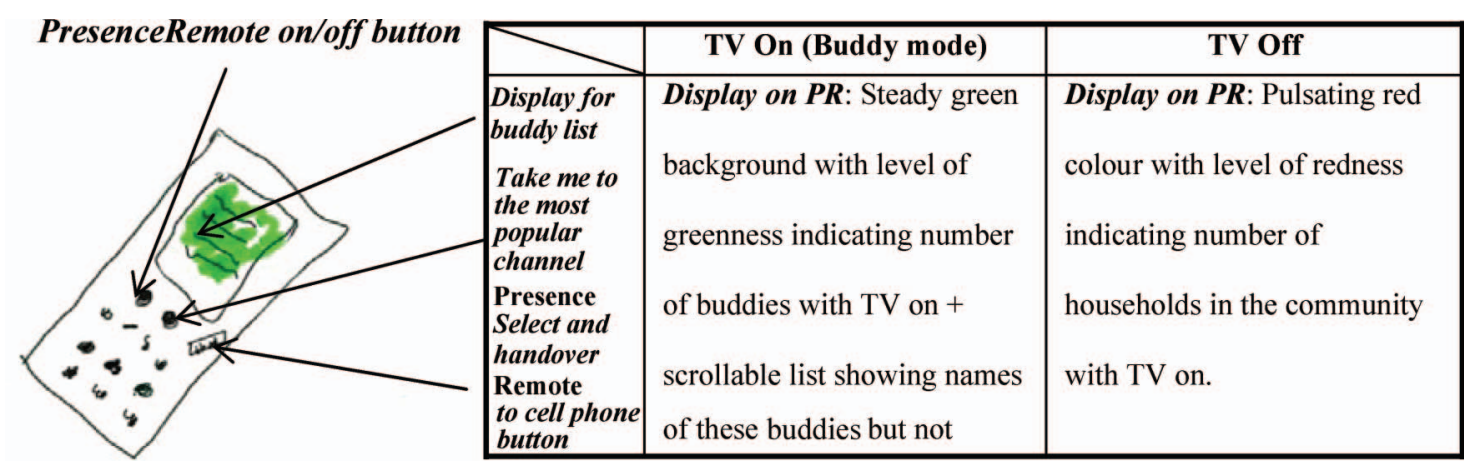

Figure 3. A sketch of the 'PresenceRemote'. 
flowing to or from the PR. Switching the PR to its $\mathrm{ON}$ state is done by pushing the 'PresenceRemote on/off button'.

2. The 'Take me to the most popular channel button' is a simple push button that when pressed takes you to the channel currently watched by the majority of people within your community with their PRs turned ON.

3. When your PR is $\mathrm{ON}$ the PR display and the functionality offered depends on whether your TV is $\mathrm{ON}$ or OFF (see the right hand table above). If your TV is OFF the display shows a pulsating red colour indicating how many people in your community have their TV turned ON. Hence, you may notice the community TV activity as you walk by the PR even when your TV is OFF. This may in turn lead you to turn on your TV on and press the 'take me to the most popular channel' button.

4. When your PR as well as your TV is ON the PR display will show the names of those of your buddies that currently have their TV and PR turned ON. We will refer to this mode as 'Buddy Mode'. When in Buddy Mode the PR will display the names of your buddies watching TV. It will however not display which channel(s) the buddies are watching. We imagine that the buddies available to the PR are a subset of the people that you already decided to include in your list of contacts on your cell.

5. Finally, the transition from noticing that a buddy of yours is watching TV to actually establishing contact is done by a handover to your cell phone. Handover meaning that you select your buddy on the list of active buddies displayed on the PR and by pressing the 'Handover to cell phone button' the PR (using Bluetooth for example) sends the Buddy ID to your cell phone. The cell phone in turn now enables you to make a regular call or send a SMS (Short Message Service), whichever you find more appropriate.

\subsection{The design rationale}

This section will discuss how the specific design decision made in the development of our 'PresenceRemote' concept reflects the overall thinking presented in this paper - how the concrete features envisioned in our concept have been chosen and designed based on the perspectives discussed.

3.3.1 Leaving the original experience as intact as possible. In order to keep the original experience of watching TV as intact as possible we do not allow avatars, emoticons or chat-messages to pop up in the middle of the regular TV content. All information having to do with the PR functionality is displayed on the remote and hence is not impinging on the regular TV content displayed on the TV. This of course is very different from the approach taken by AmigoTV where a chat space and emoticons are layered on top of the original TV pictures.

3.3.2 Linking the 'sense of community belonging' to a specific activity. The pulsating red colour indicating overall community TV activity may lead you to turn your TV on. We believe however that this display of activity may serve another more subtle and less action oriented purpose as well. We speculate that the display of community TV activity may provide you with a sense of other people's presence reminding you that you are part of a community. Furthermore, we speculate that this sense of community can be strengthened by watching the same content as the other people in your neighbourhood and thereby increase the chance to strike up a casual conversation about last night's TV show with people in the community that you run into the next day. This way of electronically enabling awareness of other people in your community is different from earlier system for electronic mediation of remote presence (e.g. Pedersen and Sokoler 1997, Mynatt 2001). These earlier standalone systems were not tied in with specific activities but relied on a general model of ambient and omnipresent detection of activities in home settings. This model of activity detection in turn raised a number of serious privacy concerns. In contrast, the PR only detects and reports information that is directly related to the single activity of watching TV. Hence, there are clear delimitations to the PR's 'reach' and it is very easy to bail out simply turn off the PR and all detection and exchange of information regarding your activities stops. By strictly tying the activity detection to a well-defined activity we aim to keep a strong sense of control and containment as opposed to the omnipresent activity monitoring mentioned above.

3.3.3 Leaving things unsaid and the notion of 'cover' activities. It could be that watching TV with our PR in some cases turns TV watching into a 'cover' activity for scouting for company. In fact, this would correspond very well with the way other activities seem to be used in order to notice and be noticed within the community. As an example, taking a walk around the facilities may be framed as a matter of getting physical exercise but in fact may be much more about increasing the probability for chance encounters with other people within the community. In line with the overall idea that leaving room for ambiguity is key to avoid stigmatization we deliberately aim for a kind of technology that does not force people to be explicit about their intentions as to why they use a particular technology at a particular time. In fact, we should not even try to entangle the different intentions but simply accept and design in ways that allows for this ambiguity. Hence, with 
the PR we deliberately allow people to leave it unarticulated whether they in fact are watching TV as an excuse to meet others. First, by design, having and using a PR should not be perceived by others as an invitation but rather as a way of saying that 'I have a PR and like other people in this community I don't mind that you know that my TV is on'. Second, by design, when in Buddy Mode it is not possible to distinguish whether a) you are looking for company b) you are simply watching TV or c) both. Also, if you do not show up on your buddies PR display there is no way for them to know whether this is due to a) your TV is off or b) you have chosen to watch TV 'in secret'.

Furthermore, we choose not to reveal the channel watched by buddies. By not displaying the choice of channel we serve some obvious privacy concerns but just as important by not making the channel explicit we bring forward openings for conversation. We speculate that this mode will stimulate communication along the lines of conversation starters such as 'what are you watching?' and 'is it any good?' or a simple 'hi'. That is, conversation starters that seem to be about the TV activity but in fact may be much more about extending a greeting - about noticing others and making oneself noticed and in that way maintain social bonds, a sense of belonging, and more important a sense of feeling safe within the community. This would indeed resemble a pattern observed during our field studies where daily rituals of communication seemed to take place not as much to exchange actual information but rather as a way to confirm that things are as usual and all right. Confirming the presence/existence of others and (re-)establishing the fact that everything seems to be as usual was often expressed as being a very important part of the daily routines amongst our interviewees. However, the existing ways of doing so were not expressed as activities with the explicit purpose of checking in on each other but expressed as part of some other activity like pseudo chanceencounters on the daily tour, the daily swapping of newspapers in the afternoon, or other daily routines where it was unsaid but quite evident that routines, to a large extent, were really about reconfirming that people in your network of friends were doing all right. In the same way we speculate that simply noticing a buddy on the PR and letting her notice you may be sufficient for you and her to feel that people caring for you are within reach should something happen. Hence, while presence indicators in AmigoTV is seen as a necessary prerequisite in order to initiate direct interaction between group members we aim for presence indicators to be of value in their own right. Also, the 'offer' made to a person entering a buddy relationship is one of reciprocity in terms of the information that is accessible to you and the information you provide. The PR does not allow lurking on your buddies' TV activities without, at the same time, giving them a chance to notice you. This of course emphasizes that we are dealing with a relationship between peers and with something radically different from a one-way monitoring system.

3.3.4 Taking advantage of other resources for human action. Finally, with the notion of a handover to regular cell phones when making actual contact, the PR aims to take advantage of and in fact rely on already earned social skills concerning the decision making involved when deciding on when to make phone calls - Is the time appropriate, is SMS the better choice? What do you normally do at this hour? When did we talk last? That is, rather than try to turn the PR into a new full scale communication device we embrace, not only the existing cell phone technology, but just as importantly, take advantage of the existing practice of telecommunication. This way of embracing an already established practice resonates immediately with our thinking about bringing forward technology that can work in concert, rather than compete, with other resources already present in the physical and social setting and our appreciation of older adults as resourceful individuals in command of a rich set of skills. In general, we seek to emphasize throughout our design that the PR only represents one of the many ways that people can notice and be noticed by others within a community. We are not aiming for the design of a monolithic 'buddy system' but for a much more humble piece of technology that may bring forward nothing more but yet another resource for social interaction.

\section{Concluding remarks}

Technology design for older people presents many interesting and important avenues for research and development. In this paper we have addressed one particular aspect of technology design that has received an increasing attention in academia and industry in recent years, namely the design of technology to support or enhance the social interaction among senior citizens. It is well known that the process of growing older is associated with issues of loneliness and that technology can help to maintain social networks. However, we are arguing that we should not neglect the fact that loneliness is taboo and that the stigma associated with being lonely needs to be considered in the design of technology. In fact, technology designed to support social interaction runs the risk of being of little use and relevance if we, as designers, fail to consider these issues as an important premise for the design. This implies, that we are faced with the somewhat eccentric challenge of designing technology that, even though it is designed to address the problem of loneliness and bring forward openings for social interaction, cannot in any way reveal that this is why people would use the technology. We are 
suggesting that we meet this challenge by looking upon ambiguity and everyday activities as resources in the design for social interaction. In particular, we argue that our design should allow people to leave their intentions of use unarticulated and hence, avoid the demand for explicitness that we so often experience when using digital technology. It is important, however, not to confuse our suggestion to leave room for unarticulated intentions of use with a lack of explicitness in the concrete interaction between humans and the digital technology we design - we are not looking to design an ambiguous interface. Our goal is to leave room for multiple interpretations of the particular reasons as to why a person chooses to use a particular technology but not how that technology should be operated.

Rather than a set of design guidelines we have presented an overall way of thinking about the design of nonstigmatizing digital technology for social interaction among senior citizens. We have presented a mindset or an attitude that we believe is a fruitful point of departure for design. It will, however, need to be refined and further substantiated through more comprehensive design work including the construction and evaluation of functional prototypes. In particular, we would like to identify and in a more precise way describe the qualities of use needed for a design to successfully make ways for social interaction while taking into account the stigma associated with being lonely. In addition, this process of refinement would require a more wide-ranging study of the everyday life of older people in senior housing communities providing us with insights that would help us determine the scope of our way of thinking about the role of digital technology in relation to social interaction within this particular group of people.

We would like to end this paper with a comment on the concept status of our example concept - the PresenceRemote. Being a concept not yet implemented and tested we can only argue and speculate about the consequences of our design decisions but cannot as yet document what the actual effects of our choices would be if the device was in real use. Even though, one should not think of the $\mathrm{PR}$ as an attempt to develop a market-leading application but merely as an example to illustrate the kind of design that may follow from the general discussions and the perspectives presented in this paper an obvious next step will include actual construction of a working PresenceRemote prototype.

\section{Acknowledgements}

We would like to thank everyone at the three senior housing facilities for inviting us to their community and for their willingness to show us around and talk about their everyday life. We are also grateful to our colleagues at Blekinge Institute of Technology for their comments and suggestions during seminars and informal discussions about this paper and to Claudia Correa for helping out with the final proofreading.

\section{References}

Aoki, P. and Woodruff, A., 2005, Making space for stories: Ambiguity in the design of personal communication systems. In Proceedings of $\mathrm{CHI}$ 05. pp. $181-190$.

Bouwen, J., Vanderlinden, K. and Staneker, T., 2005, Communication meets entertainment: Community Television. (Alcatel Technology white paper).

Brunette, K., Eisenstadt, M., Pukinskis, E. and Ryan W., 2005, Meeteetse: social well-being through place attachment. In Proceedings of CHI 2005, Student design competition.

Chan, M., Campoc, E., Lavald, E. and Estève, D., 2002, Validation of a remote monitoring system for the elderly: application to mobility measurements. Technology and Health Care, 10, pp. 391-399.

Cole, A. M. and Tran, B. Q., 2002, Home automation to promote independent living in elderly populations. Engineering in Medicine and Biology, 2002. In the proceedings of 24th Annual Conference and the Annual Fall Meeting of the Biomedical Engineering Society, pp. 2422 2423, Vol.3 (New York: IEEE).

Consolvo, S., Roessöer, P., Shelton, B., Lamarca, A., Schilit, B. and Bly, S., 2004, Technology for care networks of elders. Pervasive Computing April-June 2004. pp. 22-29.

Coppens, T., Handekyn, K. and Vanparius, F., 2005, AmigoTV: A social TV experience through triple-play convergence. (Alcatel Technology white paper).

Dalrymple, E., 2005, Aging in place: Making communities more livable for older adults (Partners for Livable Communities).

DAS, S. and Cook, D. J., 2004, Health monitoring in an agent-based smart home by activity prediction. In Proceedings of the International Conference on Smart Homes and Health Telematics, D. Zhang and M. Mokhatari (Eds), Vol. 14 of assistive technology research series, pp. 3-14 (Singapore: IOS Press).

Dourish, P., 2001, Where the action is: the foundations of embodied interaction (Cambridge, Massachusetts: MIT Press).

Gaver, W., Beaver, J. and Benford S., 2003, Ambiguity as a resource for design. In Proceedings of CHI03, pp. 233-240.

Garfinkel, H., 1967, Studies in Ethnomethodology (Englewood Cliffs, N.J.: Prentice-Hall).

Goffman, E., 1959, The Presentation of Self in Everyday Life (Garden City, NY: Anchor Books).

Goffman, E., 1963, Stigma: Notes on the Management of Spoiled Identity (Englewood Cliffs, NJ: Prentice Hall).

Goffman, E., 1967, Interaction Rituals: Essays on Face-to-Face Behaviour (Indianapolis: Bobbs-Merrill).

Hirsch, T., Forlizzi, J., Hyder, E., Goetz, J., Stroback, J. and Kurtz, C., 2000, The elder project: Social and emotional factors in the design of eldercare technologies. In Proceedings of the 2000 Conference on Universal Usability, pp. $72-80$ (Virginia: ACM Press).

McFadden, T. and Indulska, J., 2004, Context-aware environments for independent living. In Proceedings of ERA 2004, Brisbane, Australia.

Mynatt, E., Rowan, J., Craighill, S. and Jacobs, A., 2001, Digital family portraits: supporting peace of mind for extended family members. In Proceedings of CHI 01. pp. 333-340.

Pedersen, E. and Sokoler, T., 1997, AROMA: Abstract representation of presence supporting mutual awareness. In Proceedings of CHI 97. pp. $51-58$.

Perry, M., Dowdall, A., Lines, L. and Hone, K., 2004, Multimodal and ubiquitous computing systems: Supporting independent-living older users. IEEE Transactions on Information Technology in Biomedicine, $\mathbf{8}$, pp. $258-270$. 
Rantz, M. J., Marek, K. D., Aud, M., Tyrer, H. W., Skubic, M., Demiris, G. and Hussam, A., 2005, A technology and nursing collaboration to help older adults age in place. Nursing Outlook, 53, pp. 40-45.

SACKs, H., 1992, Lectures on Conversation: Volumes I and II (Oxford: Blackwell).

Sixsmith, A. and Johnson, N., 2004, A smart sensor to detect the falls of the elderly. IEEE Pervasive, 3, 43-47.

SoKoler, T., 2004, Going beyond the desktop computer with an attitude. Blekinge Institute of Technology, Dissertation Series no. 2004:04.
Thorslund, M. and Parker, M., 1995, Strategies for an aging population: expanding the priorities discussion. Aging and Society, 15, pp. $199-217$.

Vanpariss, F., Coppens, T., Godon, M. and Bouwen, J., 2004, Social Television: Enabling rich communication and community support with AmigoTV. In Proceedings of ICIN 2004, Bordeux, France (Alcatel Technology) 